\title{
Concurrence anorexia and pseudo-turner syndrome
}

\begin{abstract}
Objective: While more than twenty concurrences of anorexia nervosa with turner's syndrome (45X0) have been reported, this is the second report of a concurrence with the Turner Phenotype $(46, \mathrm{XX})$.
\end{abstract}

Method: Patient's history, hospital presentation and progress are described.

Results: Dieting would convert a plump, baby-like figure to a normally proportioned though miniature adult. There were mood swings and paranoid episodes.

Conclusions: Short stature seems a key factor when anorexia occurs in Turner's patients.

Keywords: turner's syndrome, turner phenotype, noonan syndrome, pseudo-turner syndrome, anorexia nervosa

\author{
Volume 9 Issue 6 - 2018
}

John Parkinson
Psychiatrist, Australia

Correspondence: John Parkinson, Psychiatrist in private practice (retired), P.O.Box 914, Wollongong, NSW 2520, Australia,Tel 6 I 2 42297625,

Email jpparkimson@optusnet.com.au

Received: July 05, 20I8 | Published: November 16, 2018

\section{Introduction}

The features of the syndrome described by Henry Turner in 1938 include short stature and oedema of hands and feet, often with webbing of the neck. ${ }^{1}$ In 1959 Ford and colleagues found the 45, XO chromosome anomaly in a patient of this type. ${ }^{2}$ In 1968 Noonan described a number of cases, both male and female, with similar appearance but a normal 46,XX (or 46,XY) chromosome count. ${ }^{3}$ Terminology has become confusing. Turner's syndrome is at times called the UllrichTurner syndrome, or simply gonadal dysgenesis, while Noonan's syndrome is variously called syndrome, or status, Bonnevie-Ullrich, Turner Phenotype or Pseudo-Turner syndrome. Since Pitts and Guze first reported one in $1963^{4}$ a number of concurrences have emerged of Turner's syndrome (both $45 \mathrm{XO}$ and $45 \mathrm{XO} / 46 \mathrm{XX}$ mosaic) with Anorexia Nervosa. By 1993 Muhs and Lieberz could count 21 such reports. ${ }^{5}$ Nicholls ${ }^{6}$ and Stanhope added two more in $1998 .{ }^{6}$ Callewaert and Vandereycken ${ }^{7}$ reported a further concurrence in 2007.7 As Turner's patients do not undergo puberty, it has been speculated that they may be physiologically predisposed to anorexia. $\mathrm{Kron}^{8}$ suggested that Turner's patients may be both biologically and psychologically vulnerable to Anorexia Nervosa. ${ }^{8}$ Darby \& Garfinkel, ${ }^{9}$ assessing the prevalence both of the Turner syndrome and of Anorexia Nervosa, concluded that they "do not occur together more often than one would expect by chance." " Calewaert \& Vandereycken ${ }^{7}$ (op. cit.) drew the same conclusion.

Even so, this need not deter us from considering the issues for those individuals who do experience both disorders. Muhs \& Lieberz ${ }^{5}$ (op. cit.) noted that the onset of dieting often followed the start of treatment with Oestrogen. Oestrogen is reported as lessening the appetite in animal experiments, ${ }^{10}$ while the emotional impact of a puberty induced by Oestrogen could scarcely fail to be factor in precipitating anorexia. Importantly, Muhs and Lieberz pointed out the "narcissistic wounds" inflicted in childhood by short stature and the frequency of conflicts in these families, the true need of these girls being for understanding and affection. Similarly Theilgard and Phillip suggest that any tendency to anorexia in Turner patients would more likely spring from physical rather than hormonal anomalies. ${ }^{11}$ Bruch \& Manthorpe $^{12}$ also pointed to short stature as a possible causative factor, adding their finding that concurrences with Turner's syndrome were not above the expected frequency. ${ }^{12}$ The interest of the present report, like that of the other case recently published,,$^{13}$ is that these women, with the features of Turner's but a full chromosome count, had normal hormonal function, arguing against a predisposition.

\section{Presentation and history}

The patient, who will be called Annette, was twenty-four when admitted to a public psychiatric clinic suffering from long standing anorexia nervosa. Her weight was $26.3 \mathrm{~kg}$., height $142 \mathrm{~cm}$. Hands and feet were short and oedematous. She was born to parents who subsequently had two normal sons. Malformations were obvious at birth. Her father was of normal build himself but his mother had been "short, less than five feet tall, with swollen hands and feet." His maternal grandmother had been normal in height but had "bad feet." Annette as a child was thin and often sick. She developed asthma and, though hostile to her parents, was notably dependent on her mother. At school, a little below average academically, she was socially well adjusted. Her father, a chef, would fuss over her diet. Menarche was at twelve. At sixteen she was obsessed with fear of a serial rapist who was terrorizing the neighbourhood. An episode of anorexia was treated without hospital admission. At nineteen, while working long hours as a clerk she became talkative and overactive. Diagnosed as hypomanic, she spent a month in a private hospital, receiving E.C.T. She then started in a sheltered workshop, where she remained some years - till becoming anorexic.

\section{Progress}

After admission to the clinic Annnette gained weight rapidly. A consultant endocrinologist diagnosed Bonnevie-Ullrich syndrome. From being withdrawn Annette became cheerful, talkative and happily dependent on staff, a chubby and childlike figure. Hostility to her parents, however, increased. When going home was suggested she announced that she was not her parents' child. As proof she said her two brothers had been given their father's name, Norman, as middle name but she had not! This episode was treated first with Thioridazine and then Haloperidol. On discharge Annette resumed the tyranny of her mother. Plump at first, she took to abusing bronchodilators and slimming tablets. As she again became cachectic her appearance was striking. Her infantile rotundity was gone. With dyed hair and sunken 
face carefully made up, smartly dressed, she was neither child nor dwarf but a normally proportioned adult in miniature. After falling and being too weak to get up, she was re-admitted. Her mood again became hypomanic. Constantly eating, she soon weighed $58 \mathrm{~kg}$. She started smoking, claiming that brand names on cigarette packs sent her messages. She would avoid routine programs, wandering from ward to ward. Her appearance was now once more rotund and childlike and staff were easy prey to "poor little Annette's" charms. She wore slippers and her wish to fit her stubby feet into "smart shoes" became a symbol of her renewed desire to lose weight. Shoes were specially made and she was discharged, now on a regime of Lithium. Three years later she was going from pharmacy to pharmacy demanding medications for anxiety and asthma. On readmission her weight was not a concern but she showed pressure of speech and some paranoid ideation. For a time she became depressed but when the dose of Lithium was adjusted her self esteem improved, as did she with her parents. She left hospital with the ambition of graduating from a sheltered workshop and returning to open employment.

\section{Discussion}

In Anorexia Nervosa mood disturbances are often described. ${ }^{15}$ Implications were discussed by Derek Scott in $1986 .{ }^{14}$ Pines $^{16}$ saw in the behaviour of anorexic patients the severe personality disorder of the Borderline. ${ }^{16}$ If indeed, as Bruch suggested, ${ }^{12}$ Anorexia Nervosa originates in a childhood where all needs are anticipated and development is seen as an achievement of the parents rather than the child, it amounts to the failure of individuation/separation which Masterson saw as the basis of the Borderline syndrome. ${ }^{18}$ Annette's hostility to both parents certainly evokes Mack's picture of the basic anger of the Borderline, whose changing moods can include psychotic episodes. ${ }^{18}$ Turner's syndrome, also, carries psychiatric proclivities of its own. Cardoso and colleagues found that more than half of the Turner's patients whom they surveyed suffered a psychiatric illness. ${ }^{19}$ Feng $^{20}$ and others reported a similar result in Hong Kong. ${ }^{21}$ Several authors, such as Brich \& Manthorpe $^{21}$ (op. cit.) have implicated short stature as a factor in Anorexia Nervosa. Fieldsend ${ }^{22}$ mentioned "awareness of short stature with an appearance of stockiness." 22 Muhs \& Lieberz ${ }^{5}$ (op. cit.) wrote of the "narcissistic wounds" of shortness and other deficits. McCauley and colleagues studied a group of Turner's patients and other girls of short stature. ${ }^{23} \mathrm{Kron}^{8}$ (op. cit.) noted that many anorexic patients were below average height. A picture remarkably like Annette was described by Sabbath et al. in their study of seven girls lacking ovarian function: "With four of the girls overweight was a definite issue. Their obesity......with their short stature gave them a rather grotesque appearance..... When ......Carol D.....had succeeded in losing weight ...... a remarkable change took place. She dyed her hair.....began to wear high heels." ${ }^{24}$ A degree of cognitive impairment in space-form perception has been found in Turner's syndrome. ${ }^{25}$ This may well contribute in their case to the anorexic's bewildering claim of being "too fat." A more recent study of 80 Turner's patients found impairment affecting executive function and social skills, more marked in the 55 whose $\mathrm{X}$ chromosome was maternally derived. ${ }^{26,27}$

\section{Conclusion}

This report presents the second recorded case of a concurrence of anorexia nervosa with the pseudo-turner syndrome $(46, \mathrm{XX})$. There have been more than twenty reports of concurrences with the turner syndrome $(45, \mathrm{XO})$ itself. Several authors have suggested short height as a factor in the onset of anorexia and this case supports that. The patient's ambivalence towards her parents was quite typical of anorexia nervosa and her brief psychotic episode has precedents both in Turner's syndrome and in anorexia nervosa.

\section{Acknowledgements}

None.

\section{Conflict of interest}

The author declares that there is no conflict of interest.

\section{References}

1. Turner HH. A syndrome of infantilism, congenital webbed neck and cubitus valgus. Endocrinology. 1938;23(5):566-574.

2. Ford CE, Jones KW, Polani PE, et al. A sex-chromosome anomaly in a case of gonadal dysgenesis (Turner's syndrome). The Lancet. 1959;273(7075):711-713.

3. Noonan JA. Hypertelorism with Turner phenotype. A new syndrome with associated congenital heart disease. American $J$ Dis. Child. 1968;116(4):373-380.

4. Pitts EN and Guze EB. Anorexia nervosa and gonadal dysgenesis (Turner's syndrome). Amer J Psychiat. 1963;119:1110-1102.

5. Muhs A, Lieberz K. Anorexia nervosa and Turner's syndrome. Psychopathology. 1993;26(1):29-40.

6. Nicholls D, Stanhope R. Turner's syndrome, anorexia nervosa and anabolic steroids. Archives of Disease in Childhood. 1998;79(1):94-95.

7. Callewaert T, Vandereycken W. Development and treatment of anorexia nervosa in patients with Turner syndrome. A case study. Tijdschr Psychiatr. 2007;49(3):183-193.

8. Kron L. Anorexia Nervosa and Gonadal Dysgenesis: further evidence of a relationship. Arch Gen Psychiatry. 1977;34(3):332-335.

9. Darby PL, Garfinkel PE. Anorexia nervosa and Turner syndrome: cause or coincidence? Psychological Medicine. 1981;11(1):141-145.

10. Young JK. Estrogen and the etiology of anorexia nervosa. Neuroscience and Biobehavioral Reviews. 1991;15(3):321-327.

11. Theilgard A, Phillip J. Concurrence of Turner's syndrome and Anorexia Nervosa. Acta Psych Scand. 1975;52(1):31-35.

12. Bruch H. Eating Disorders. London. Routledge and Kegan Paul;1974:277-280.

13. Arvaniti A, Maria Samakouri, Flora Keskeridou, et al. Concurrence of Anorexia Nervosa and Noonan syndrome. European Eating Disorders Review. 2014;22(1):32-38.

14. Scott DW. Anorexia Nervosa: A Review of Possible Genetic Factors. International J Eating Disorders. 1986;5(1):1-20.

15. Cantwell DP. Anorexia Nervosa: an affective disorder? Arch. Gen. Psychiatr. 1977;34(9):1087-1093.

16. Pines M. Anorexia nervosa. Scientific Bulletin of the British PsychoAnalytical Society. 1973;69:21-34.

17. Masterson JF. Psychotherapy of the Borderline Adult. New York Brunner Mazel. 1976:37-38.

18. Mack JE. Borderline States: an historical perspective. Mack JE (ed.) Borderline States in Psychiatry. New York. Grune and Stratton. 1975. 
19. Cardoso G. Current and lifetime psychiatric illness in women with Turner's syndrome. Gynecol Endocrinol. 2004;19(6):313-319.

20. Feng Z. Turner's syndrome with mental disorders resembling schizophrenia and affective disorder. Hong Kong J Psychiatr. 2001 11(3).

21. Brich M, Manthorpe T. Short stature as a possible etiological factor in anorexia nervosa. Act Psychiatr Scand. 1987;76(3):328-332.

22. Fieldsend B. Anorexia nervosa and Turner's syndrome. Brit. J Psychiat. $1988 ; 152(2): 270-271$.

23. McCauley E, Ito J, Kay T.. Psychosocial functioning in girls with Turner's syndrome and short stature: social skills, behavior and self concept. $J$ Amer Acad Child Psychiat. 1986;25(1):105-112.
24. Sabbath JC. Psychiatric observations in adolescent girls lacking ovarian function. Psychosomatic Medicine.1961;23(3)224-231.

25. Money J. Cytogenic and psychosexual incongruities with a note on spaceform blindness. Am J Psychiatry. 1963;119:820.

26. Skuse DH. Evidence from Turner's syndrome of an imprinted X-linked locus affecting cognitive function. Nature. 1977;387(6634):705-708.

27. Shaffer JW. A specific cognitive defect observed in gonadal dysplasia. $J$ Clin Psychol. 1962;18:403. 